\title{
Cooperativas e inclusión en la Ciudad de México
}

\author{
Martha Izquierdo \\ Doctora en Derecho. Universidad Nacional Autónoma de México, \\ especialista en temas de derecho social y cooperativo. \\ Pertenece al Sistema Nacional de investigadores (nivel I)
}

Sumario: 1. Introducción. 2. El Cooperativismo en México. 3. El Cooperativismo en la Ciudad de México. 4. Programas y actividades de inclusión. 5. Actividades de inclusión femenina. Bibliografía y fuentes.

Resumen: Las cooperativas en la Ciudad de México (Capital del país) conjuntamente con algunos Planes y Programas del gobierno de esta Ciudad han sido encaminadas hacia una economía social y solidaria para la generación de empleos, lo cual ha sido una forma acertada para muchas personas que han quedado fuera del mundo laboral, especialmente para el sector femenino. Resultando por tanto relevante la participación de todos los actores tanto en los procesos de capacitación como en la formación de cooperativas. Es por ello que la acción pública desde el gobierno debe seguir impulsando el actual modelo cooperativo, toda vez que resulta ser una alternativa viable desde el punto de vista económico y social, esto es: para la generación de empleos y para la reconstrucción del tejido social.

Palabras clave: Ciudad de México; cooperación; inclusión.

Abstract: Cooperatives in Mexico City (Capital of the country) together with some Plans and Programs of the government of this City have been directed towards a social and solidary economy for the generation of jobs, which has been an apt way for many people who have been outside of the working world, especially for the female sector. Therefore, the participation of all the actors in both the training processes and in the formation of cooperatives is relevant. That is why public action from the government must continue to promote the current cooperative model, since it turns out to be a viable alternative from the economic and social point of view, that is: for the generation of jobs and for the reconstruction of the social tissue.

Keywords: Mexico City; cooperation; inclusion. 


\section{Introducción}

La Ciudad de México Capital del país, durante más de dos décadas (1997 a 2017) ha logrado crear un espacio permanente de coordinación y trabajo a través de la implementación de foros, congresos, talleres y otras formas de capacitación y educación cooperativa, encaminado casi siempre al alcance de una política de empleo incluyente y de fomento cooperativo, así como al establecimiento de un marco legal de apoyo al cooperativismo, lo cual se ve reflejado en la ley de Fomento Cooperativo para el Distrito Federal, (2006), en el programa General de Fomento Cooperativo (2009), así como en diversas acciones, que determinan todo un modelo de vanguardia en el país con la promoción del cooperativismo y de otras formas de economía social y solidaria, pero por otra parte cabe aclarar que el cooperativismo generalmente no se ejerce por la mayoría de los Estados de la República, con algunas excepciones como en la Ciudad de México.

En efecto, el Gobierno de la Ciudad de México, ha impulsado una red intercooperativa, junto con gobiernos y sindicatos encaminados hacia una autentica economía social y solidaria para generar empleos, demostrando con ello que solo con el cambio del modelo económico basado en el cooperativismo será posible encontrar la solución al problema del desempleo.

Por lo que se refiere al sector laboral para la mujer, se mantiene toda una política bien organizada de apoyo a este sector, ya que actualmente la oferta laboral se encuentra en crisis, pero sobre todo por la discriminación hacia ellas existe, lo cual ha mermado su aspecto salarial.

De tal suerte que la equidad de género en la Ciudad de México, dentro de una cultura democrática es un tema que en las últimas décadas ha ido cobrando una gran importancia, reconociéndosele ampliamente para la elaboración de planes y programas de desarrollo, por lo que resulta interesante destacar la labor que se ha venido realizando en apoyo a las mujeres.

En consecuencia puede afirmarse que la red intercooperativa con gobiernos y sindicatos, encaminados hacia una economía social y solidaria en la Ciudad de México para la generación de empleos, ha sido una forma acertada, para muchas personas que han quedado fuera del mundo laboral, resultando relevante la participación de todos los actores tanto en los procesos de capacitación como en la formación de cooperativas. Al mismo tiempo la acción pública desde el gobierno, debe seguir impulsando este modelo cooperativo, toda vez que resulta 
ser una alternativa viable desde el punto de vista tanto social como económico y no solo para la generación de empleos sino también para la reconstrucción del tejido social.

Esta política, de protección al empleo y al fomento cooperativo, así como de un marco legal, expresado tanto en la Ley de Fomento Cooperativo, como en el Programa para la ejecución del mismo, han constituido un valioso antecedente de vanguardia en la Ciudad de México como no se había visto en muchos años.

Todas estas acciones, vienen a proyectar una alternativa de organización económica sumamente distinta a las políticas neoliberales y antidemocráticas que han subsistido en todo el país con la firma del Tratado de Libre Comercio entre México, Estados Unidos y Canadá (NAFTA, por sus siglas en inglés), con las graves consecuencias que esto ha traído consigo por la acumulación del capital en unas cuantas manos como es el desempleo, la economía informal, el crimen organizado, el narcotráfico, la migración de personas hacia los Estados Unidos etc. Lo cual refleja una auténtica descomposición del tejido social y como consecuencia la delincuencia en nuestro país, por lo anterior es necesario que aun cuando se observe una cierta debilidad del movimiento cooperativo y se observe que aún falta un mayor conocimiento sobre el cooperativismo, este debe ser considerado como una alternativa económicamente viable por sus ideales y principios que conlleva.

\section{El cooperativismo en México}

Los orígenes del cooperativismo en México se ubican en 1839, fecha en que se fundó en Orizaba Veracruz la primera caja de ahorros con las características de una sociedad cooperativa.

Sus fundadores fueron empleados y artesanos, inspirados en ideas de cooperación y ayuda de mutua, que en un tiempo les fueron transmitidas por los socialistas utópicos franceses.

En efecto estas ideas de cooperación tuvieron en nuestro país un efecto muy particular pues al ser defendidas por los socialistas utópicos franceses, así como por ideólogos anarquistas, vinieron a sustituir lo que en nuestra tradición existía en las comunidades indígenas con el

1 IZQUIERDO, Martha. "Comentarios en torno a las sociedades cooperativas en México». Boletín de la Asociación Internacional de Derecho Cooperativo. Vol. 46, 2012 p. 56. 
trabajo colectivo y la propiedad comunal de las tierras en los famosos: «Calpullis²».

Sin embargo las instituciones de tipo cooperativo que surgieron en México, nacen en medio de grandes luchas sociales y agitaciones populares en defensa de algunos ideales, identificándose desde sus inicios con los movimientos: campesino y obrero (1800 a 1903), por tanto puede decirse que en nuestro país las diversas leyes de sociedades cooperativas que han existido, reflejan realmente su momento histórico.

El origen legal de las empresas cooperativas lo fue el Código de Comercio de 1889-1890, en virtud de que en su capítulo VII les dedico 22 preceptos y las consideró como sociedades mercantiles confundiéndolas con la sociedad anónima, la cual podía construirse como empresa de responsabilidad limitada o ilimitada y no se les dio ningún tratamiento especial.

De hecho en el citado Código de Comercio la sociedades cooperativas fueron consideradas como una variante de las sociedades mercantiles y fueron definidas de esa manera, con todas sus características generales como fueron: el número de socios, el capital variable, su responsabilidad solidaria e ilimitada o limitada a una determinada suma menor igual o mayor que el capital social, etc. ${ }^{3}$

No obstante una de las grandes aportaciones que trajo consigo la Revolución Mexicana de 1910 fue que estableció a través de la constitución de 1917 un nuevo "orden social y económico» así como un nuevo "proyecto nacional», consecuentemente al crearse las bases para un sector social de la economía se insertaron automáticamente las empresas cooperativas delimitadas por los artículos: 28, 27,31F. IV; 73F. VII y X; 123 y 131 Constitucionales.

El número de cooperativas que han existido en México en los últimos años según datos recabados por la Secretaria de Relaciones Exteriores (SRE), se estiman de la siguiente manera:

Para el año 2000, se tenían registradas a más de 20.000 cooperativas de las cuales según el Instituto Nacional de Nacional de Estadística y Geografía (INEGI), para el mismo año tan solo se encontraban activas 10.156 repartidas de las siguiente forma: 6925 de producción y 3.231 de consumo, abarcando todas ellas un total de 464.206 socios sin considerar las cajas populares de ahorro que para 1995 mantenían una

2 IZQUIERDO, Martha. «Problemas de las empresas cooperativas en México». Boletín de la Asociación Internacional de Derecho Cooperativo. Vol.43 España, 2010. p. 97.

3 LABRIEGA VILLANUEVA, Pedro Alfonso. La Reforma de legislación Mercantil. México Porrúa 1985, 234. 
membresía de más de 1.5 de socios con la constitución de la Caja Popular Mexicana, integrada por más de 60 cajas populares 4 .

Para el año 2011 se estimaba que operaban 15.000 cooperativas en su mayoría de consumo y de producción de bienes y servicios en las que participaban más de 7 millones de personas, de las cuales 5 millones aproximadamente participaban en el sector de ahorro y préstamo popular, siendo las restantes las que se ocupaban de la producción y el consumo, las cuales representaban aproximadamente el 7\% de la población total ${ }^{5}$.

Sin embargo y pese a los datos aportados por el Instituto Nacional de Estadística y Geografía (INEGI), actualmente resulta difícil la identificación de un número confiable de cooperativas porque la Ley General de Sociedades Cooperativas de 1994 «desclaso» a las cooperativas del sector obrero, normándolas en una ley especial sujetándolas a la legislación comercial lo cual iba en contra de su propia naturaleza.

En efecto, la ley actual considero a las empresas cooperativas del sector obrero como sociedades mercantiles con ánimo de lucro, considerándolas además para efectos económicos en la categoría de micro, pequeñas y medianas empresas, las cuales conforman un vasto universo de más de 4 millones de unidades en el país.

De hecho cabe mencionar que uno de los grandes problemas que existen actualmente para el sector cooperativo en México, se debe principalmente al modelo económico que prevalece. Esto es que el capitalismo mexicano bajo el modelo neoliberal excluye al cooperativismo, descartándolo en los esquemas de desarrollo nacional, aun cuando la ley lo reconozca en sus ordenamientos fundamentales, además lo proyecta como sinónimo de retroceso, subversión y fracaso, por lo tanto el cooperativismo en México no se respeta ni se ejerce por el gobierno federal ni por la mayoría de los gobiernos de las entidades federativas con algunas excepciones ${ }^{6}$.

Por consecuencia se desconoce al cooperativismo y no se aplican sus principios universales y compromisos con la comunidad pues se carece de una educación, capacitación y cultura cooperativa, capaz de estimular la creación y desarrollo de nuevas empresas.

Tampoco existen apoyos y financiamientos y los que llegan a existir son escasos y caros, tampoco existen instancias públicas de asistencia

4 Cooperativas en México. Fuente INEGI 2000.

5 Cooperativas una alternativa en México.14.III.2011. http://www.ipsonoticias.net/ nota. asp? idnews=97763Inter Press Service.

6 Tiempo de Mujeres. Formación de cooperativistas y cooperativas. Unión de juristas de México. http://mujeres por la democracia.blogspot.mx. p. 3. 
técnica especializada en el tema de cooperativas como es la administración, contabilidad, finanzas, mercados, etc. ${ }^{7}$.

La falta de programas oficiales así como de una banca de desarrollo social de apoyo a las cooperativas con créditos flexibles, dificulta aún más su desarrollo, aunado todo esto a la gran estructura política y económica del país, determinada por relaciones capitalistas de exportación y subordinación del trabajo asalariado, saqueo de recursos naturales, prevalencia de monopolios, bancos extranjerizados y empresas transnacionales que poseen y contratan absolutamente todo, pero lo más lacerante es la ignorancia y falta de compromiso de nuestros dirigentes sobre la naturaleza del cooperativismo que lejos de apoyar a este sector lo han agobiado hasta su extinción, bajo la idea de que las cooperativas van en contra del sistema capitalista ${ }^{8}$

Actualmente las cooperativas en México son consideradas como elementos que gradualmente conducen al socialismo, cuando en realidad lo que se persigue es una correlación de fuerzas y una alternativa económica en el modo de producción prevaleciente en el país, toda vez que el actual modelo económico nos ha empobrecido dejando a más del $50 \%$ del total de la población del país en la pobreza, que actualmente asciende en su totalidad a: 119 millones 530,753 personas y la respuesta no se ha hecho esperar pues actualmente contamos con grandes problemas como la migración, la economía informal, el crimen organizado, narcotráfico, levantamientos sociales etc.

La trayectoria de la economía mexicana y sus múltiples consecuencias en materia social desde la entrada en vigor del Tratado de Libre Comercio (NAFTA por sus siglas en inglés) hasta nuestros días, sugiere que las metas a lograr como el mayor crecimiento, mejores empleos, mejores ingresos para la población etc. es una tarea aún pendiente, pues lejos de ello lo que se observa es que el país depende cada vez mas de las importaciones para satisfacer sus demandas, incrementándose la informalidad urbana y la migración hacia los Estados Unidos, tareas que son urgentes atender por ser tanto asistencialistas como preventivas de inconformidades mayores que bien podrían agudizar el clima de frustración y de descontento social y no obstante que contamos con diversos artículos constitucionales que garantizan un mejor modelo de vida para los mexicanos, lo hasta aquí expuesto expresa una realidad diferente.

7 DOMínGUEZ, Juan Gerardo. Reticulaciones entre empresas auto sugestivas. El fin del dinero y restauración del crédito social. México, Editorial FOMIX, ECO SOL, Colegio de Tlaxcala, SE PUEDE. 2005, p. 67.

8 Tiempo de Mujeres, op. cit., p. 5. 


\section{El Cooperativismo en la Ciudad de México}

La Ciudad de México antes llamada Distrito Federal (D.F.) por ser la sede de los tres poderes federales (Ejecutivo, Legislativo y Judicial), ha sido gobernada desde hace varios años por un partido de oposición como es el Partido de la Revolución Democrática (PRD) desde el año de 1997, el cual dio inicio a una serie de programas sociales, dando un reimpulso al cooperativismo de la mano de algunas iniciativas de ley que fueron adoptadas posteriormente en 2006.

En efecto, en el año de 2006 fue aprobada la ley de Fomento Cooperativo y en el año de 2009 en aquel entonces el Gobierno del Distrito Federal puso en vigor el Programa General de Fomento Cooperativo, para encauzar algunas variantes de la economía social ${ }^{9}$ como es el fortalecimiento del empleo

Observándose así que desde entonces prevalece el movimiento cooperativo en la Ciudad de México, el cual se encuentra integrado por el sistema cooperativo y sus organismos, bajo el apoyo de la administración pública que durante más de dos décadas (1997 a 2018) ha logrado crear un espacio permanente de coordinación y trabajo a través de la implementación de foros, congresos, talleres, exposiciones y otras formas de capacitación y educación cooperativa.

Bajo este sistema se ha implementado una política de empleo y de fomento cooperativo, así como del establecimiento de un marco legal de apoyo al cooperativismo, lo cual se ve reflejado en las leyes anteriormente citadas.

Actualmente se cuenta con el Programa: Apoyo para el Desarrollo de Sociedades Cooperativas de la Ciudad de México y Subprograma de Impulso Cooperativo (2018) así como de diversas acciones que se han ido realizado a través del tiempo como fue la creación de un padrón que para el año 2013 contaba con más de 500 cooperativas, lo que determinaba un modelo de vanguardia en una entidad del país, con la promoción del cooperativismo y de otras formas de economía social y solidaria.

En la Ciudad de México, Capital del país, De acuerdo al último censo de población y vivienda 2010, realizado por el Instituto Nacional de Estadística Geografía e Informática (INEGI), existían un total de 8, 851.080 habitantes, de los cuales $52.17 \%$ correspondían al sexo femenino y el $47.83 \%$ al sexo masculino, teniendo como característica poblacional el ser una de las entidades con mayor densidad de población,

9 Cooperativas, una alternativa en México, op. cit., p. 3. 
esto es: 5.953 habitantes por kilómetro cuadrado, lo cual es un gran reto.

La población económicamente activa (PEA) en la Ciudad de México, según cifras reportadas por INEGI para 2010 era de 4.173 .981 personas, de las cuales el $53.6 \%$ eran hombres y el $46.4 \%$ mujeres. Asimismo con respecto a la población económicamente ocupada, existían 3.910.864 personas, mientras que las personas desempleadas eran 263.117 personas, las cuales han ido en aumento.

Respecto a la población considerada como no económicamente activa, se reportaba un total de $2.898,462$ personas, quienes no realizaban ninguna actividad productiva, representando un 34\% de la población total del Distrito federal como son: estudiantes, amas de casa, jubilados etc.

Para 2015 se estima que exista un total de 8.918.653 habitantes de los cuales 4.687 .003 son mujeres y 4.231 .650 son hombres, pero será hasta el censo poblacional de 2020 cuando pueda reportarse nuevamente un padrón confiable. ${ }^{10}$

Por otra parte la Ciudad de México, ha registrado constantemente tasas de desempleo por encima del total nacional, lo que se atribuye al carácter complejo del mercado laboral en la zona, caracterizado por una alta proporción de profesionistas y técnicos, un sector productivo que aporta el $18 \%$ del PIB, una fuerte segmentación de la demanda y la presión que se ejerce con la población proveniente de diversos municipios conurbados ${ }^{11}$

Otro de los datos que resultan interesantes de la Ciudad de México es que la mayor fuente generadora de empleo es la microempresa, que ocupa 1.619.285 trabajadores, representando el 39.47\% de la PEA, y en un segundo lugar lo ocupan las pequeñas empresas, en las que laboran 798.727 personas, representando el $19.43 \%$ de la PEA, posteriormente se encuentra la mediana empresa en un tercer lugar que ocupa a 573.210 trabajadores, constituyendo el $13.97 \%$ del total de la PEA, lo que significa que tanto la micro, pequeña y mediana empresa generan cerca del $72.91 \%$ de los empleos.

El problema del desempleo y del subempleo en esta ciudad se convierten en un problema tanto social como económico, por ello a lo largo de estas administraciones se ha buscado reducir el impacto que sobre el tejido social esto trae consigo, implementando políticas ac-

10 http://cuentame.inegi.org.mx/monografias/informacion/df/poblacion

11 EVALUACIÓN INTERNA 2013 DEL PROGRAMA PARA LA PROMOCIÓN, FORTALECIMIENTO E INTEGRACIÓN COOPERATIVA. SECRETARIA DEL TRABAJO Y FOMENTO AL EMPLEO. GACETA OFICIAL DEL DISTRITO FEDERAL 28.VI.2013. 
tivas para la creación de empleos, a través de programas de fomento cooperativo que generalmente han estado a cargo de la Secretaria del Trabajo y Fomento al Empleo, lo que ha permitido que cientos de personas entre 25 y 45 años de edad puedan contar con un ingreso para sacar adelante a sus familias, ante la imposibilidad de reincorporarse al mercado laboral ${ }^{12}$.

En efecto, con la creación de empresas cooperativas a través de todos estos años se ha logrado que la población pueda contar con un empleo, ayudando a reducir los índices de desempleo que afectan a un gran número de personas en su mayoría jóvenes, muchos de ellos con estudios medio superior y profesionales, evitando con ello que se sumen a la economía informal que prevalece en más de un $60 \%$ en el país, o bien que se sumen a la delincuencia organizada ante la falta de oportunidades, impulsando con ello una cultura cooperativa en todos los ámbitos de producción ${ }^{13}$

Por tanto podemos decir que el esfuerzo que se ha realizado en la Ciudad de México durante más de dos décadas, ha sido con la finalidad de resolver el problema del desempleo, lo que es un claro ejemplo de organización de la fuerza laboral.

\section{Programas y actividades de inclusión}

Dentro de las actividades que más se han destacado a partir de la elaboración de la Ley General de Fomento Cooperativo para el Distrito Federal (2006), han sido:

Año 2006. Al inicio de este periodo fue la elaboración y distribución de uniformes escolares elaborados por empresas cooperativas que se constituyeron con desempleados y subempleados principalmente, todos ellos mayores de 35 años.

Se inició este programa con 1800 personas inscritas en los cursos de: "formación de empresas cooperativas para el autoempleo", con una duración de 2 meses, durante las cuales acudieron 6 horas diarias de lunes a viernes a 4 centros establecidos y con una beca mensual. Asimismo se les capacito en materia organizacional, fiscal, legal y administrativa, habiéndose logrado primeramente los acuerdos con organismos autónomos y sindicales para la adquisición de terrenos a efecto de constituir las sedes de las cooperativas en los ramos de: cul-

12 Ídem.

13 MÉXICO: LA CREACIÓN DE COOPERATIVAS HA PERMITIDO REDUCIR EL EMPLEO EN EL D.F. 10.II.2012. http:////aciamericas.coop/mexico-la-cracion-de-cooperativas 
tura, alimentos e informática que posteriormente dieron empleo a más de 2.000 personas, cuyos productos fueron adquiridos en su mayor parte por la administración central, por las distintas delegaciones del aquel entonces DF y por las diferentes dependencias autónomas o paraestatales ${ }^{14}$.

La idea original de este programa fue la de combatir la tasa de desempleo abierto, que al inicio de esta gestión (2006) afectaba a más de 200 mil personas como consecuencia, de una política neoliberal que prevalece en nuestro país desde 1984.

Por tanto, las primeras 30 cooperativas se dedicaron al ramo de costura, habiendo reunido a 1800 personas de las cuales el $90 \%$ fueron mujeres cuya edad oscilaba en 35 años de edad, en adelante, toda vez que en este país a esa edad se tiene gran dificultad para laborar no obstante su experiencia o capacidad.

Para el año 2007 con el objeto de promover el autoempleo en la ciudad de México, y específicamente para los sectores poblacionales del alta, muy alta y media marginación, se creó el programa: «creación de sociedades cooperativas" que tenía por objeto brindar apoyo a personas en situación de vulnerabilidad, para ese efecto desde ese año se impulsaron mecanismos de creación de sociedades cooperativas en áreas de producción y posteriormente se publicaron los lineamientos y mecanismos de operación. Su trabajo inicial fue la elaboración de 340 mil uniformes escolares, iniciando así un mercado laboral que equivalía a varios millones de pesos ${ }^{15}$.

Para el año 2008 fueron modificados estos lineamientos y mecanismos de operación, dejando como responsable del programa a la Dirección Ejecutiva de Asuntos Jurídicos.

En enero del 2009 se creó el Programa General de Fomento Cooperativo y se publicaron las reglas de operación de dicho programa en las que tanto la Dirección Ejecutiva de Asuntos Jurídicos, la Dirección de Patrocinio Jurídico y la Dirección de Programas Especiales eran responsables ${ }^{16}$.

Para 2010 nuevamente las reglas de operación sufren modificaciones que establecen como área responsable únicamente a la Dirección

14 GÓMEZ FLORES, Laura. «Inicia el GDF cursos de formación de empresas cooperativas para el autoempleo». Periódico la Jornada 19.IV.2007.

15 Ídem.

16 REGLAS DE OPERACIÓN DEL PROGRAMA DE CREACIÓN Y FOMENTO DE SOCIEDADES COOPERATIVAS 2014. GACETA OFICIAL DEL DISTRITO FEDERAL 300.i. 2014. P. 328. 
Ejecutiva de Asuntos Jurídicos y se crea otro programa denominado: «Creación y Fomento de Sociedades Cooperativas»" ${ }^{17}$.

Con este programa se pretendió garantizar el derecho al trabajo de un sector vulnerable en la Ciudad de México, lo cual se hizo conforme a los Planes y Programas de Desarrollo que operan para todo el país y conforme a los programas de empleo en Ciudad de México.

Cabe mencionar que este programa originalmente estaba dirigido a la población del entonces Distrito Federal, económicamente desocupada que ascendía a 299,745 personas. ${ }^{18}$

Para este mismo año (diciembre de 2010) existían más de 360 cooperativas en productos y servicios diversos, las cuales habían generado 12.000 empleos directos y 36.000 indirectos.

Se observa que durante 2007 a 2010 se capacito a más de 9.000 personas de las cuales 6.700 fueron mujeres de 35 años de edad, los grupos de población localizados fueron principalmente: vendedores ambulantes, vendedores en el metro, trabajadoras sexuales, plomeros y prestadores de servicio de mantenimiento entre otras más.

Se destaca la importancia que este año tuvo la firma del convenio multilateral: "por el empleo y la economía social para la reactivación en el DF», cuyo objetivo fue mejorar la capacitación para el impulso de las cooperativas en lo relativo a la distribución de productos y servicios para las administraciones locales, para el cual fue necesario diversas modificaciones a la legislación, para obtener recursos que permitiera poner en marcha proyectos productivos en el rubro laboral, de apertura de negocios, uso de suelo etc. ${ }^{19}$.

Para 2011, la tasa de desempleo en el Distrito Federal, fue variable con tendencia a la alza. En ese mismo año los asociados de 7 cooperativas en su mayoría mujeres habían elaborado 3.500 .000 uniformes escolares que recibirían gratuitamente alumnos de las escuelas a nivel pre-escolar, primaria y secundaria, bajo el marco del programa: «que buena puntada».

Para el mes de febrero del mismo año, el Secretario del Trabajo, informó a la ciudadanía que se habían capacitado en la formación de empresas cooperativas a 9.136 personas en 486 cursos, de los cuales 6.872 habían sido mujeres mayores de 35 años, logrando concen-

17 Ídem.

18 Fuente INEGI, Encuesta Nacional de Ocupación y Empleo. Indicadores estratégicos de ocupación y empleo en el Distrito Federal 2012.

19 Ciudad de México: fomento estatal a la generación de empleo a través de cooperativas. COOPERATIVISMO EN MOVIMIENTO. VI Encuentro de Investigadores LatinoAmericanos de Cooperativismo. Cuba 9.XII.2010. 
trarse 929 proyectos productivos bajo la idea de que ante la crisis de empleo que prevalecía, las empresas nacionales o cooperativas resultaban ser una alternativa viable, no solo para generar empleos sino también para distribuir la riqueza de forma equitativa, sin afán de lucro, la cual implica todo un cambio de mentalidad en las relaciones de los trabajadores.

Asimismo para fomentar el cooperativismo fue necesario organizar la fuerza de trabajo a fin de obtener una mejor capacidad productiva y no quedar solo en empresas pequeñas, así como en el establecimiento de políticas públicas por parte de los gobiernos de las distintas Delegaciones de la Ciudad de México, para impulsar la capacitación y el financiamiento de proyectos productivos.

Para lograr estos objetivos el Gobierno de ésta Ciudad impulsó una red intercooperativa, junto con algunos sindicatos encaminados hacia una autentica economía social y solidaria para generar empleos, demostrando con ello que solo con el cambio del modelo económico basado en el cooperativismo sería posible encontrar la solución al problema del desempleo. ${ }^{20}$

Otras cooperativas que han participado en este proyecto son principalmente: Ollintzin, Cuentzin, Nuevo impulso, Huitzilin y creaciones del sureste entre otras más, impulsando con ello un modelo de desarrollo regional basado en las potencialidades de los habitantes de barrios, pueblos y Colonias de ésta Ciudad.

Cabe destacar que de la cifra publicada en el anuario estadístico del INEGI, sobre el Distrito Federal (actualmente Ciudad de México), para 2011, reportó que el $65.34 \%$ de las sociedades cooperativas se encontraban en el sector terciario de la economía, en el secundario el $13.46 \%$ y el $19.16 \%$ en el primario. Siendo las más relevantes las de prestación de servicios, las relacionadas con el comercio, las agropecuarias y las manufactureras ${ }^{21}$.

En el año de 2012 cobran una gran relevancia las cooperativas, en virtud de que fue declarado por la Organización de Naciones Unidas (ONU) como: 2012 el año internacional de las empresas cooperativas. El diagnostico conocido para 2012 en la Ciudad de México, es que cientos de persona entre 29 y 45 años de edad pudieron contar con un ingreso para sacar adelante a sus familias ante la imposibilidad de incorporarse al mercado laboral. Se llevaron a cabo 5 ferias cooperati-

20 Ante la crisis económica fomentar cooperativismo en México. Mirón Lince. Grupo Fórmula. Copyright 2011.

21 Secretaria del Trabajo y Fomento al Empleo. Gaceta Oficial del Distrito Federal. 28.VI.2013. 
vas donde se aportaron y bienes y servicios y productos elaborados por esas unidades 22 .

En la primera reunión del Consejo Consultivo del Programa de Fomento Cooperativo se acordó la elaboración de políticas públicas como labor central, cuyo fin estuvo orientado a modificar en parte el actual modelo económico, así como reforzar la coordinación con los movimientos cooperativos locales y Nacionales impulsando la cultura cooperativa en todos los ámbitos de la producción en México y de acuerdo con los datos aportados por la Dirección de Estudios y Estadísticas del Trabajo (DEET), se reporta un padrón de 803 cooperativas en la Ciudad de México con lo cual es importante mencionar que con el programa: Para la Promoción, Fortalecimiento e Integración Cooperativa 2012 se apoyó económicamente a 105 sociedades cooperativas más, cubriendo un porcentaje del $13.07 \%$ de estas empresas ${ }^{23}$.

Para el año 2013 se contó con un presupuesto de $\$ 20.000 .000$ (veinte millones de pesos 00/MN) cuya finalidad fue la de beneficiar aproximadamente a 1.000 socios cooperativistas de al menos 100 empresas cooperativas para su consolidación, fortalecimiento, conservación y mejora de la calidad de sus empleos, la inversión se llevó en los siguientes rubros: capital fijo, capital de trabajo e inversión diferida, por un monto de hasta $\$ 200,000.00$ (doscientos mil pesos 00/MN.)

Para 2014 la meta fue realizar 885 acciones de fomento al autoempleo y asesoría toda vez que el Programa de Creación y Fomento de Sociedades Cooperativas, buscaba garantizar el ejercicio de los derechos de los habitantes de la Ciudad de México como son el derecho al trabajo y al agua, con acciones diseñadas con un enfoque de equidad y Derechos Humanos, que incluye el acceso a la información y participación en los planes y programas que impulsa el actual Gobierno, para avanzar en la eliminación de la desigualdad existente ${ }^{24}$.

Para el año de 2016 se cuenta con el Programa de Apoyo para el Desarrollo de las Sociedades Cooperativas, cuyo objetivo es contribuir a la generación y consolidación de fuentes de trabajo dignas entre los habitantes de la Ciudad de México, ofreciendo como alternativa de organización a las sociedades cooperativas, cuya intención es favorecer tanto a socios como a socias, brindado servicios de asesoría, capacitación o asistencia técnica especializada, además de apoyos económicos para adquisición de equipo, maquinaria o servi-

22 http: ACl Américas, op. cit., p. 2.

23 Gaceta Oficial del DF. 2014, op. cit., p. 3.

24 Ídem. 
cios enfocados a fortalecer procesos productivos, de comercialización y/o de promoción. 25

Como puede observarse, el gobierno de la Ciudad de México, consciente de la importancia que reviste la empresa social y solidaria así como múltiples beneficios colectivos, elevó el cooperativismo a rango de política pública, orientada al cambio económico y social, a través de diversos programas, cuyo fundamento legal se encuentra en los siguientes artículos:

\section{Artículo 5. De la ley de Protección de Fomento al Empleo del Distrito Federal que menciona:}

Corresponde al jefe de Gobierno del Distrito Federal a través de la Secretaria del Trabajo y fomento al empleo, entre otras las siguientes obligaciones:

VII. Fortalecer a los sectores público privado, así como el fomento cooperativo generadores de empleo, mediante el establecimiento de programas y acciones de apoyo empresarial, vinculación y comercialización de los bienes y servicios que produzcan, así como la proveeduría de sus productos a la administración pública local.

En el artículo 23 de la Ley Orgánica de la Administración Pública del Distrito Federal que asigna a la Secretaria de Trabajo y Fomento al Empleo, entre otras funciones:

I. Promover y consolidar acciones que generen ocupación productiva, y XXIV. Fomentar y poyar la organización social para el trabajo y el auto empleo.

En el artículo 9, Inciso A Fracción II de la Ley de Fomento Cooperativo para el Distrito Federal, que establece que corresponde a la Secretaria de Trabajo y Fomento el Empleo:

«ll. Impulsar las actividades de fomento cooperativo en el Distrito Federal y proporcionar, por si o a través de personas bajo su revisión, físicas o morales, asesoría, capacitación y adiestramiento para la constitución, consolidación, administración y desarrollo de las Sociedades Cooperativas, así como para la producción, comercialización y consumo de los bienes y servicios necesarios para los actos que establece el artículo $4^{\circ}$ de este Ley».

A su vez el Programa General de Fomento Cooperativo del Distrito Federal marca en el punto $V .22$ programa:

25 Secretaria del Trabajo y Fomento al Empleo. https://www.trabajo.cdmx.gob.mx 
(Inciso 3) de vinculación laboral con el seguro de desempleo, con el fomento cooperativo, la economía solidaria y otros programas sociales.

(Inciso 7) de financiamiento a proyectos productivos cooperativos.

Asimismo se planteó también el seguro de desempleo, toda vez que contempla entre sus facultades principales el fortalecimiento de los sectores público, privado y social, así como el fomento cooperativo, que es generador de empleo, mediante el establecimiento de programas y acciones de apoyo empresarial, vinculación, distribución y comercialización de los bienes y servicios que se produzcan, así como la proveeduría de sus productos a la administración pública local.

En general todos estos componentes han tenido como parte central lograr una ciudad con oferta de empleos, convertirla en una ciudad cuya revalorización del trabajo que tuviera como base la sustentabilidad económica, la preservación del ecosistema y un medio ambiente sano, un desarrollo social y humano de las clases, géneros, grupos sectores y personas que componen la comunidad, como son: hombres, mujeres, niños y niñas, jóvenes, adultos, personas con capacidades diferentes etc. a fin de materializar en la actual Ciudad de México la dignidad y el bienestar de sus habitantes ${ }^{26}$.

\section{Actividades de inclusión femenina}

Por lo que se refiere a la mujer en el sector laboral como hemos visto se tiene toda una política bien organizada de apoyo en la Ciudad de México, ya que debido a la escasa oferta que para ellas existe, el trabajo bien remunerado se encuentra en crisis, pero sobre todo por causas de la discriminación es que se ha mermado el aspecto salarial.

En efecto la desigualdad de género ha sido y sigue siendo una realidad en México y en el mundo entero, no obstante en algunos países han centrado su atención en amortiguar este problema y es reconocido como objeto de atención de política pública, debido en gran parte por la acción de organizaciones de mujeres de movimientos feministas, de comunidades académicas y organismos internacionales como la ONU y muchos más que han conjuntado esfuerzos a fin de recobrar su dignidad en estos espacios.

De tal suerte que la equidad de género en una cultura democrática es un tema que las últimas décadas ha ido cobrando una gran im-

${ }^{26}$ REGLAS DE OPERACIÓN, op. cit., p. 2. 
portancia tanto en el plano nacional como internacional, reconociéndosele ampliamente para la elaboración de planes y programas de desarrollo27.

Se observa que junto con la Organización de Naciones Unidas (ONU), México ha participado activamente, en algunos programas a favor de la mujer como en la Asamblea General de la Organización de Naciones Unidas (AGONU), en la Comisión de la Condición Jurídica y Social de la mujer (CSW), en el Índice de Equidad de Género (EG), en la División para el avance de las mujeres (DAM), en la Comisión de Derechos Humanos (CDH), en el Fondo de Desarrollo de las Naciones Unidas para la Mujer (UNIFEM) en el Instituto Internacional de Investigaciones y Capacitación de las Naciones Unidas para la promoción de la Mujer (INSTRAM). ${ }^{28}$ Entre otros más.

Así mismo nuestro país ha participado en la Comisión Interamericana de las Mujeres (CIM) formado parte activa de las iniciativas y resoluciones aprobadas por dicha Comisión, evidenciándose una gran participación de todos los actores sociales. Para el efecto de conocer la situación que guarda nuestro país con relación a la equidad de género se ha tomado como referencia el «índice de disparidad entre géneros a nivel internacional» (TGGG) de 2009 elaborado por el Foro Económico Mundial (WEF por sus siglas en inglés):

\begin{tabular}{lc}
\hline \multicolumn{1}{c}{ Indicadores } & $\begin{array}{c}\text { Posición de México } \\
\text { (inv. en 140 países) }\end{array}$ \\
\hline Participación económica y oportunidades & 114 \\
Logros educativos & 90 \\
Poder político & 65 \\
Salud y supervivencia & 1 \\
\hline
\end{tabular}

Índice: Foro Económico Mundial29.

En dicho cuadro México se encontraba entre los países con mayor inequidad de género, lo cual ya indicaba una gran marginación y atraso. ${ }^{30}$

27 México a la retaguardia en equidad de género.30.10.2009. Cimacnoticias. http:// www.cimacnoticias.com/site/09103003-Mexico-a-la-retagu.39817.0.html

28 Ídem.

29 FORO ECONÓMICO MUNDIAL. ÍNDICE DE DISPARIDAD ENTRE GÉNEROS 2009. http://www.weforum.org/

30 Ídem. 
Bajo el mismo Informe Global de la Brecha de Género WEB pero de 2016 se observa que México ahora se encuentra en el lugar 66, por debajo de Kenia, El Salvador y Vietnam, observándose que nuestro país disminuyó en cuanto a la proporción femenina de profesionales y trabajadoras técnicas, también se encuentra entre los últimos países en cuanto a la participación y oportunidad económica de las mujeres, en cambio obtiene una buena calificación en el subíndice de salud y supervivencia. En dicho reporte se destaca que las mujeres realizan una mayor cantidad de trabajo no remunerado en relación con los hombres, asimismo resalta la cantidad de mujeres jóvenes que no estudian ni trabajan. ${ }^{31}$

En base a lo anterior es por lo que resulta interesante destacar la labor que el en la Ciudad de México se ha venido realizando en apoyo a las mujeres, toda vez para el segundo semestre de 2010 según cifras del INEGI, la población trabajadora en México que ganaba más de cinco salarios mínimos, registró una pérdida histórica de 178 mil 727 salarios, de los cuales de 24.000 el $73 \%$ eran mujeres ${ }^{32}$

Para el 2011 fueron instruidas cerca de 10.000 personas en la formación de empresas cooperativas, de las cuales el 74\% fueron mujeres, esto es cerca de 7.000 personas.

Para 2016 la Secretaría de Trabajo y Fomento al Empleo (ST Y FE) conjuntamente con el Instituto de las Mujeres de la Ciudad de México (INMUJERES CDMX), firmaron un convenio de colaboración con el objetivo de implementar acciones tendientes a fomentar el empleo, promover la capacitación para el trabajo, la economía del cuidado, reforzar la ocupación productiva, otorgar protección social a las mujeres en materia laboral, así como buscar su autonomía y empoderamiento económico, con el fin de impulsar la igualdad de género y el pleno ejercicio de derechos y oportunidades entre mujeres y hombres.

Se estima que esta dependencia de enero a junio de 2016 vinculó a 13 mil 589 mujeres a un empleo, lo que representa el 51\%. El 67\% de la población beneficiaria de los cursos de capacitación son mujeres, el $55 \%$ en autoempleo y el $68 \%$ en cooperativas. ${ }^{33}$

En consecuencia puede afirmarse que la red intercooperativa con gobiernos y sindicatos, encaminados hacia una economía social y soli-

31 FORO ECONÓMICO MUNDIAL. ÍNDICE DE DISPARIDAD ENTRE GÉNEROS 2016. https://imco.org.mx/competitividad/informe-global-de-la-brecha-de-genero-2016-viaweb.

32 Población Trabajadora en México. Fuente: INEGI 2010.

33 http://data.inmujeres.edmx.gob.mx/convenio-de-colaboracion-porempoderamiento-economico 
daria en la Ciudad de México para la generación de empleos, ha sido una forma acertada aunque distinta, para muchas personas que han quedado fuera del mundo laboral, resultando relevante la participación de todos los actores tanto en los procesos de capacitación como en la formación de cooperativas, al mismo tiempo que la acción pública desde el gobierno, ha impulsado este modelo cooperativo, toda vez que resulta ser una alternativa viable desde el punto de vista tanto social como económico, para la generación de empleos y para la reconstrucción del tejido social.

No obstante lo hasta aquí planteado, los comentarios que se han hecho van en el siguiente sentido:

Que no obstante el tiempo transcurrido para llevar a cabo estos programas no han sido suficientes para apuntalar la economía social, ya sea por el peso determinante de las políticas federales y se repercusión en la ciudad o bien por la falta de claridad, cohesión y voluntad política de los distintos equipos de los gobiernos capitalinos.

Que el movimiento cooperativo no ha sido lo suficientemente capaz de movilizar las políticas públicas sobre esta materia, más allá de lo que hasta ahora se ha logrado, dependiendo en buena parte de la acción conjunta de algunos funcionarios, encargados de la materia del trabajo, de la previsión social y del fomento al empleo, de algunos dirigentes de las empresas cooperativas más emblemáticas del país y del apoyo de investigadores e intelectuales especializados en el cooperativismo ${ }^{34}$.

Que los gobiernos de orientación de izquierda del gobierno capitalino, aun cuando han estado apoyados en el constitucionalismo social que se desprende del artículo 25 Constitucional, no han logrado destinar los suficientes recursos para la ejecución y cumplimiento de los programas de políticas públicas, lo cual fue ampliamente recomendado por diversas organizaciones como la organización Internacional del Trabajo (OIT), pese a que se cuenta con un marco legal desde 2006 y un programa a ejecutar desde $2009^{35}$.

Sin embargo nuestra opinión es en el sentido de considerar que los primeros pasos ya se ha dado, puesto que el movimiento cooperativo de la Ciudad de México, bajo el apoyo de un gobierno democrático (PRD), durante más de dos décadas (1997-2018), ha logrado crear un espacio permanente de coordinación y trabajo, mediante la organización de foros, congresos, talleres, expo ferias y otras formas de edu-

34 Tiempo de mujeres, op. cit., p. 4.

35 Ídem. 
cación cooperativa que ha sido incluyente especialmente para el sector femenino, que ha motivado un impacto en la generación de empleo, en la inversión y en la educación aunque todavía precarios.

Consideramos que esta política, de protección al empleo y al fomento cooperativo, así como de un marco legal de apoyo al cooperativismo expresado tanto en la Ley de Fomento Cooperativo así como en los Programas para la ejecución del mismo, han constituido un valioso antecedente de vanguardia en la Ciudad de México como no se había visto en muchos años, de tal suerte que la promoción del cooperativismo y de otras formas de economía social han logrado contar con un número considerable de cooperativas, 500 aproximadamente.

Consideramos que todas estas acciones, vienen a proyectar una alternativa de organización económica sumamente distinta a las políticas neoliberales y antidemocráticas que han subsistido en todo el país, con las graves consecuencias que esto ha traído consigo como es el desempleo, la economía informal, el crimen organizado, el narcotráfico, la emigración de personas hacia los Estados Unidos etc. lo cual refleja una auténtica descomposición del tejido social y como consecuencia una organización de la delincuencia, por lo anterior consideramos que aun cuando se observa una cierta debilidad del movimiento cooperativo y una falta de conocimiento del cooperativismo como organización social y solidaria, puede ser considerado como una alternativa económicamente viable por sus ideales y principios que conlleva.

Las grandes cooperativas como Pascual Boing, Cruz Azul, El GruIlo (Jalisco), TRADOC y muchas otras más en el ámbito pesquero son una gran referencia que demuestra que es posible llegar a niveles muy altos.

Si realmente se quiere alcanzar una mejor economía para todos, una mejor y más justa distribución de la riqueza y de oportunidades incluyentes, este es el camino y si bien no se han dado los resultados esperados en este tiempo, no debemos olvidar que el camino del cooperativismo es un largo camino, que en otros países se forjo a través de varias generaciones y luchas, por lograr los grandes resultados toda vez que éste se sustenta de las experiencias y acciones de sus propios triunfos y fracasos, asumiendo compromisos políticos y sociales por la democracia y por un nuevo proyecto de nación.

Finalmente consideramos que es necesario un mayor esfuerzo conjunto y un mayor compromiso para seguir aplicando este tipo de políticas públicas tendiente a alcanzar una mejor distribución de la riqueza. Este proyecto cooperativo debe ser considerado como una auténtica alternativa económica y no solamente para la ciudad de México sino para todo el país en su conjunto. 


\section{Bibliografía y fuentes}

Ciudad de México. Fomento estatal a la generación de empleo a través de cooperativas. Cooperativismo en movimiento. VI Encuentro de Investigadores Latino-Americanos de Cooperativismo. Cuba 9.XII.2010.

CONVENIO de colaboración por empoderamiento económico. 2016.

Cooperativas una alternativa en México.14.III.2011.

Domínguez, Juan Gerardo. Reticulaciones entre empresas auto sugestivas. El fin del dinero y restauración del crédito social. México, Editorial FOMIX, ECO SOL, Colegio de Tlaxcala, SE PUEDE. 2005.

EVALUACIón interna 2013 del Programa para la Promoción, Fortalecimiento e Integración Cooperativa. Secretaría del Trabajo y Fomento al Empleo. Gaceta Oficial del Distrito Federal 28.VI.2013.

Foro Económico Mundial. Índice de disparidad entre géneros 2009. http:// www.weforum.org/

Foro Económico Mundial. Índice de disparidad entre géneros 2016.

Fuente INEGI, Encuesta Nacional de Ocupación y Empleo. Indicadores estratégicos de ocupación y empleo en el Distrito Federal 2010.

Fuente INEGI, Encuesta Nacional de Ocupación y Empleo. Indicadores estratégicos de ocupación y empleo en el Distrito Federal 2012.

Gómez FLoRes, Laura. «Inicia el GDF cursos de formación de empresas cooperativas para el autoempleo». Periódico la Jornada 19.IV.2007.

http://data.inmujeres.edmx.gob.mx/convenio-de-colaboracion-porempoderamiento-economico

http://www.ipsonoticias.net/nota.asp?idnews=97763Inter Press Service

https://imco.org. mx/competitividad/informe-global-de-la-brecha-de-genero2016-via-web

INEGI. Información Ciudad de México. Población. 2018 http://cuentame.inegi. org.mx/monografias/informacion/df/poblacion

IZQUIERDO, Martha. "Comentarios en torno a las sociedades cooperativas en México». Boletín de la Asociación Internacional de Derecho Cooperativo. Vol. 46. 2012.

IzQuierdo, Martha. «Problemas de las empresas cooperativas en México». Boletín de la Asociación Internacional de Derecho Cooperativo. Vol.43. 2010.

Labriega Villanueva, Pedro Alfonso. La Reforma de legislación Mercantil. México Porrúa 1985.

México a la retaguardia en equidad de género.30.10.2009. Cimacnoticias. http://www.cimacnoticias.com/site/09103003-Mexico-a-laretagu.39817.0.html

México: la creación de cooperativas ha permitido reducir el empleo en el D.F. 10.II.2012. http:////aciamericas.coop/mexico-la-cracion-de-cooperativas 
Reglas de operación del Programa de Creación y Fomento de Sociedades Cooperativas 2014. Gaceta Oficial del Distrito Federal 300.i. 2014.

Secretaría del Trabajo y Fomento al Empleo. https://www.trabajo.cdmx.gob.mx Secretaría del Trabajo y Fomento al Empleo. Gaceta Oficial del Distrito Federal. 28.VI.2013.

Tiempo de mujeres. Formación de cooperativistas y cooperativas. Unión de juristas de Mexico... 7.14.2010. http://mujeresporlaemocracia.blogspot.mx 